\title{
Hippocampal and cerebellar atrophy in patients with Cushing's disease
}

\author{
${ }^{*}$ Till Burkhardt, MD, ${ }^{1}$ Daniel Lüdecke, MD, ${ }^{2}$ Lothar Spies, PhD, ${ }^{3}$ Linus Wittmann, MSc, ${ }^{2}$ \\ Manfred Westphal, MD, ${ }^{1}$ and Jörg Flitsch, MD1
}

Departments of ${ }^{1}$ Neurosurgery and ${ }^{2}$ Psychiatry, University Medical Center Hamburg-Eppendorf; and 3jung diagnostics GmbH, Hamburg, Germany

OBJECT Cushing's disease (CD) may cause atrophy of different regions of the human brain, mostly affecting the hippocampus and the cerebellum. This study evaluates the use of 3-T MRI of newly diagnosed patients with CD to detect atrophic degeneration with voxel-based volumetry.

METHODS Subjects with newly diagnosed, untreated CD were included and underwent 3-T MRI. Images were analyzed using a voxelwise statistical test to detect reduction of brain parenchyma. In addition, an atlas-based volumetric study for regions likely to be affected by CD was performed.

RESULTS Nineteen patients with a mean disease duration of 24 months were included. Tumor markers included adrenocorticotropic hormone (median $17.5 \mathrm{pmol} / \mathrm{L})$, cortisol ( $949.4 \mathrm{nmol} / \mathrm{L})$, and dehydroepiandrosterone sulfate $(5.4 \mu \mathrm{mol} / \mathrm{L})$. The following values are expressed as the mean \pm SD. The voxelwise statistical test revealed clusters of significantly reduced gray matter in the hippocampus and cerebellum, with volumes of $2.90 \pm 0.26 \mathrm{ml}$ (right hippocampus), $2.89 \pm 0.28$ $\mathrm{ml}$ (left hippocampus), $41.95 \pm 4.67 \mathrm{ml}$ (right cerebellar hemisphere), and $42.11 \pm 4.59 \mathrm{ml}$ (left cerebellar hemisphere). Healthy control volunteers showed volumes of $3.22 \pm 0.25 \mathrm{ml}$ for the right hippocampus, $3.23 \pm 0.25 \mathrm{ml}$ for the left hippocampus, $50.87 \pm 4.23 \mathrm{ml}$ for the right cerebellar hemisphere, and $50.42 \pm 3.97 \mathrm{ml}$ for the left cerebellar hemisphere.

CONCLUSIONS Patients with untreated CD show significant reduction of gray matter in the cerebellum and hippocampus. These changes can be analyzed and objectified with the quantitative voxel-based method described in this study.

http://thejns.org/doi/abs/10.3171/2015.8.FOCUS15324

KEY WORDS hippocampus; cerebellum; atrophy; Cushing's disease

$\mathrm{C}$ USHING's disease (CD) is caused by excessive production of adrenocorticotropic hormone (ACTH) by a pituitary adenoma, ${ }^{23}$ and usually reveals itself with a typical elevation of blood levels of ACTH, cortisol, and dehydroepiandrosterone sulfate (DHEA-S). ${ }^{9}$ Besides changes of their outward appearance and internal morbidities, 12,29 patients usually present with psychological disorders such as depression and anxiety ${ }^{20,22,33}$ as well as memory deficit and lack of concentration. ${ }^{34,38}$ In CD these changes have been linked to atrophy of the brain in general, ${ }^{26,32}$ and different subregions of the brain, $, 3,6,28,32$ caused by excess glucocorticoids and their neurotoxic effects. ${ }^{19,24}$ Structures of the limbic system - the hippocampus, the anterior cingulate gyrus, and the amygdala-are affected by long-term exposure to glucocorticoids because these areas are part of the stress response system and are rich in mineralocorticoid receptors and glucocorticoid receptors. ${ }^{10,13,25}$

Another region of potential reduction of volume is the cerebellum, which is prone to atrophic degeneration in long-term hypercortisolism. ${ }^{28,31}$

Most studies regarding brain atrophy in CD or Cushing's syndrome (CS) are based on subjective evaluation of MR images and manual measurements of different regions of interest. ${ }^{6,32,34}$ Studies based on objective, voxelbased measurements of brain atrophy in CD are very rare and have dealt with patients in long-term remission from CD. ${ }^{3,37}$

ABBREVIATIONS $\mathrm{ACTH}=$ adrenocorticotropic hormone; $\mathrm{CD}=$ Cushing's disease; $\mathrm{CS}=$ Cushing's syndrome; $\mathrm{DHEA}-\mathrm{S}=$ dehydroepiandrosterone sulfate; $\mathrm{GM}=$ gray matter; MNI = Montreal Neurological Institute; MPRAGE = magnetization-prepared rapid gradient echo; TIV = total intracranial volume; VBM = voxel-based morphometry; WM = white matter.

SUBMITTED June 30, 2015. ACCEPTED August 27, 2015.

INCLUDE WHEN CITING DOI: 10.3171/2015.8.FOCUS15324.

* Drs. Burkhardt and Lüdecke contributed equally to this work. 
We hypothesize that elevation of tumor markers and the duration of disease may correlate with decreases of regional cerebral volume in patients with untreated $C D$, particularly in the hippocampus and cerebellum. We aim to explore the feasibility and accuracy of standard T1weighted 3-T MRI with voxel-based morphometry (VBM) and an atlas-based volumetry approach to detect cerebral atrophy in patients with untreated CD.

\section{Methods}

This prospective, single-center study was approved by the local ethics committee of the University Medical Center Hamburg-Eppendorf. All patients gave written informed consent for participation in this study and the subsequent use of all study- and treatment-related data for scientific publication.

\section{Inclusion/Exclusion Criteria}

Male and female patients who were 18 years or older and who had previously untreated CD were included. Patients who were younger than 18 years or patients with a history of any structural brain pathology (e.g., traumatic brain injury, tumor, or stroke) were excluded from this study.

\section{Laboratory Investigation}

Blood draws were performed the day prior to transsphenoidal surgery to measure plasma levels of ACTH, cortisol, and DHEA-S.

\section{Image Acquisition}

Patients underwent MRI prior to transsphenoidal surgery. Images of all patients and the 40 healthy control volunteers were acquired with a 3-T MR scanner (Siemens Skyra) using a standardized MR protocol comprising a high-resolution 3D, T1-weighted, magnetization-prepared rapid gradient echo (MPRAGE) imaging sequence for enhanced tissue contrast. The following settings were used: TR $1900 \mathrm{msec}$, TE $2.46 \mathrm{msec}$, TI $900 \mathrm{msec}$, flip angle $9^{\circ}$. Slice thickness was $0.94 \mathrm{~mm}$ and pixel size was $0.94 \mathrm{~mm}$ for both directions.

\section{Image Analysis}

The MR images were segmented and stereotactically normalized to the Montreal Neurological Institute (MNI) space by using the combined segmentation and registration approach implemented in the SPM8 software package (released April 2009; Wellcome Trust Centre for Neuroimaging). Prior tissue probability maps for gray matter (GM), white matter (WM), and CSF were used to assist segmentation and registration, which were generated from a population of 662 healthy elderly subjects. ${ }^{21}$ Maps feature an isotropic resolution of $1 \mathrm{~mm}$. For all analyses, we used the default settings of the unified segmentation engine. The unified segmentation approach yielded 3 stereotactically normalized tissue maps (GM, WM, and CSF) with a voxel volume of $1 \mathrm{~mm}^{3}$ and intensities between 0 and 1 . The determinant of the Jacobian matrix of the transformation field was applied locally to ensure that the volume was preserved after stereotactic normalization (modula- tion). Stereotactically normalized and modulated tissue maps were further processed by applying a CSF mask to compensate for misclassification at the interface between CSF and bone. ${ }^{18}$ Stereotactically normalized, modulated, and CSF-masked GM tissue maps were subjected to further analysis.

Total GM, WM, and CSF volumes were estimated by summation of all voxel values of the respective tissue maps multiplied by the voxel volume. The sum of GM, WM, and CSF volume is the total intracranial volume (TIV).

\section{Voxelwise Statistical Analysis}

For group comparison on the voxel level, a voxelwise statistical test was configured using the standard general linear model of SPM8 (VBM) to test GM reduction in the brain parenchyma. A corresponding binary mask composed of brain tissue voxels was used. Voxelwise statistical tests were performed on CSF-masked, stereotactically normalized, and modulated GM tissue maps restricted to voxels belonging to the brain tissue mask with an isotropic voxel grid; the grid size was $2 \mathrm{~mm}$. The voxel volume was $0.008 \mathrm{ml}$. VBM produces parametric maps with the same dimension and voxel volume. We applied a 1-sided 2-sample t-test including age and TIV as covariates to test for GM reductions in the CD group as opposed to the normative database of healthy controls. Sex is not included since the TIV eliminates sex differences. ${ }^{17}$ Prior to testing, GM tissue maps of both groups were further aligned using a high-dimensional elastic registration technique (DARTEL). Finally, each GM tissue map was smoothed by an isotropic gaussian filter with a full width at halfmaximum of $4 \mathrm{~mm}$, which is considered to be sufficient in combination with DARTEL. ${ }^{17}$ The test was restricted to voxels defined by the brain tissue mask. The cluster threshold was set to 125 voxels; i.e., clusters with volumes of smaller than $1 \mathrm{ml}$ were discarded. Parametric maps for $\mathrm{p}<5 \mathrm{E}-07$ were generated. Clusters were considered significant for $\mathrm{q}<0.05$, corrected for multiple comparisons using the false discovery rate method. ${ }^{11}$

\section{Atlas-Based Volumetry}

In addition, we performed atlas-based volumetry ${ }^{18}$ for regions likely to be affected by $\mathrm{CD}$, such as the hippocampus and cerebellum. Volumetric measures were calculated by a voxel-by-voxel multiplication and subsequent integration of stereotactically normalized, modulated, and CSFmasked GM tissue maps with predefined binary masks from different atlases. Binary masks for the left and right cerebellum were derived from the International Consortium for Brain Mapping (ICBM) 152 nonlinear atlas (version 2009), with a 1-mm isotropic resolution. ${ }^{15}$ Resulting volumes for the left and right hemisphere were denoted as CVL and CVR (cerebellar volume left and right, respectively). For atlas-based hippocampal volumetry, hippocampus masks for the left and the right hemisphere derived from a freely available probabilistic cytoarchitectonic atlas ${ }^{14}$ were used separately, yielding 2 subvolumes for each brain hemisphere; HVL and HVR (hippocampal volume left and right, respectively). The masks comprise the cornus ammonis (CA1-CA4) and fascia dentate substructures as defined by Amunts and coworkers, ${ }^{2}$ and feature an isotropic resolution of $1 \mathrm{~mm}$. 
All volumes were corrected for TIV and age to reduce intersubject variability of no interest. For this purpose, first bilinear regression analysis was performed in the group of controls (40 subjects), with volume as a dependent variable and TIV and age as predictors, and then all volumes were adjusted to the mean age (63 years) and mean TIV (1424 $\mathrm{ml}$ ) of the control group by using a bilinear formula. The Student 2-sample t-test (1-sided or 2-sided) was used to statistically compare absolute and adjusted volumes from atlas-based volumetry of patients with $\mathrm{CD}$ and healthy controls.

\section{Results}

\section{Patient Characteristics and Results of Blood Draws}

Between November 2013 and May 2015, 32 patients met the inclusion criteria. Of these, 25 patients ( 20 female and 5 male) participated in this study; the 7 other patients did not want to participate. The median age was 46 years (with a range of 20-68 years and SD of 12.8 years).

As shown in Table 1, the median estimated duration of disease was 24 months (range 0-156 months, SD 34 months), median preoperative ACTH levels were 17.5 $\mathrm{pmol} / \mathrm{L}$ (range 11.9-33.6, SD 5.2), median cortisol levels were $949.4 \mathrm{nmol} / \mathrm{L}$ (range 405.7-2288.0, SD 454.6), and median DHEA-S levels were $5.4 \mu \mathrm{mol} / \mathrm{L}$ (range 1.3-18.0, SD 4.4) preoperatively.

\section{Preoperative MRI}

Twenty-five consecutive patients underwent 3-T MRI with a nonenhanced MPRAGE sequence; 6 MRI studies had to be discarded from further investigation for technical reasons, resulting in 19 scans that were analyzed for this study.

Sixteen patients showed microadenomas on standard sellar MRI, 2 patients had macroadenomas, and 1 tumor showed signs of invasive growth into the cavernous sinus. In 1 patient the preoperative MRI revealed a negative result; therefore the patient underwent cavernous sinus blood sampling as described by us in $2015 .{ }^{8}$

\section{Voxelwise Statistical Analysis}

The groupwise comparison of GM tissue images obtained in patients with $\mathrm{CD}$ and in healthy controls yielded 4 separate clusters of reduced GM in the CD group in the left and right limbic system and left and right cerebellum (Fig. 1). All clusters were significantly reduced in GM volume, with $\mathrm{q}<0.0001$ (false discovery rate corrected).

The highest $t$ score (8.14) was found within the cluster located in the left cerebellum, with peak MNI coordinates of $-28 \mathrm{~mm},-76 \mathrm{~mm}$, and $-54 \mathrm{~mm}$. The cluster size was $5.84 \mathrm{ml}$ (730 voxels). Other significant clusters were located in the right cerebellum, with $5.98 \mathrm{ml}$ (747 voxels; $\mathrm{t}$ score of peak $=7.87$; peak MNI coordinates $=22,-76$, $-54)$; and right and left hippocampal areas, with $2.61 \mathrm{ml}$

TABLE 1. Clinical data in 19 patients with $C D^{*}$

\begin{tabular}{|c|c|c|c|c|c|c|c|}
\hline Case No. & Sex & $\begin{array}{c}\text { Micro- or } \\
\text { Macroadenoma }\end{array}$ & Age in Yrs & $\begin{array}{c}\text { Preop ACTH } \\
\text { (pmol/L: } 2.2-13.3 \text { ) }\end{array}$ & $\begin{array}{c}\text { Preop Cortisol } \\
\text { (nmol/L: 138-690) }\end{array}$ & $\begin{array}{l}\text { Preop DHEA-S } \\
(\mu \mathrm{mol} / \mathrm{L}: 2.5-7.5)\end{array}$ & $\begin{array}{l}\text { Duration of Illness } \\
\text { in Mos }\end{array}$ \\
\hline 1 & $F$ & Micro & 48 & 13.5 & 552.0 & 4.7 & 0 \\
\hline 2 & $\mathrm{M}$ & Micro & 31 & 26.4 & 1484.9 & 10.2 & 30 \\
\hline 3 & $F$ & Micro & 46 & 16.7 & 759.0 & 5.4 & 156 \\
\hline 4 & $F$ & Micro & 53 & 13.0 & 1093.0 & 4.5 & 36 \\
\hline 5 & $\mathrm{~F}$ & Micro & 68 & 16.5 & 623.8 & 9.5 & 26 \\
\hline 6 & $F$ & Micro & 46 & 20.0 & 485.8 & 1.3 & 42 \\
\hline 7 & $F$ & Macro & 45 & 11.9 & 505.1 & 3.9 & 24 \\
\hline 8 & $\mathrm{~F}$ & Micro & 66 & 23.2 & 1192.3 & 8.3 & 36 \\
\hline 9 & $\mathrm{~F}$ & Micro & 51 & 20.7 & 742.4 & 9.1 & 24 \\
\hline 10 & $\mathrm{~F}$ & Macro & 20 & 33.6 & 2288.0 & 2.0 & 18 \\
\hline 11 & M & Micro & 48 & 19.5 & 1275.1 & 7.5 & 24 \\
\hline 12 & $F$ & Micro & 44 & 15.1 & 949.4 & 2.7 & 6 \\
\hline 13 & $\mathrm{~F}$ & Micro & 53 & 17.7 & 436.1 & 2.4 & NR \\
\hline 14 & $\mathrm{~F}$ & Micro & 24 & 20.3 & 822.5 & 3.4 & NR \\
\hline 15 & $\mathrm{~F}$ & Micro & 33 & 16.0 & 974.3 & 14.3 & 12 \\
\hline 16 & $\mathrm{~F}$ & Micro & 37 & 14.0 & 1070.9 & 10.6 & 10 \\
\hline 17 & $\mathrm{~F}$ & Micro & 53 & 19.6 & 1266.8 & 18.0 & 36 \\
\hline 18 & $F$ & Micro & 29 & 17.5 & 1040.5 & 5.0 & 24 \\
\hline 19 & $\mathrm{~F}$ & Micro & 52 & 15.4 & 405.7 & 8.5 & 24 \\
\hline Median & & & 46 & 17.5 & 949.4 & 5.4 & 24 \\
\hline Minimum & & & 20 & 11.9 & 405.7 & 1.3 & 0 \\
\hline Maximum & & & 68 & 33.6 & 2288.0 & 18.0 & 156 \\
\hline SD & & & 12.8 & 5.2 & 454.6 & 4.4 & 34.14 \\
\hline
\end{tabular}

NR $=$ not reported.

* The standard units and range of normal values for hormones are given in parentheses. 

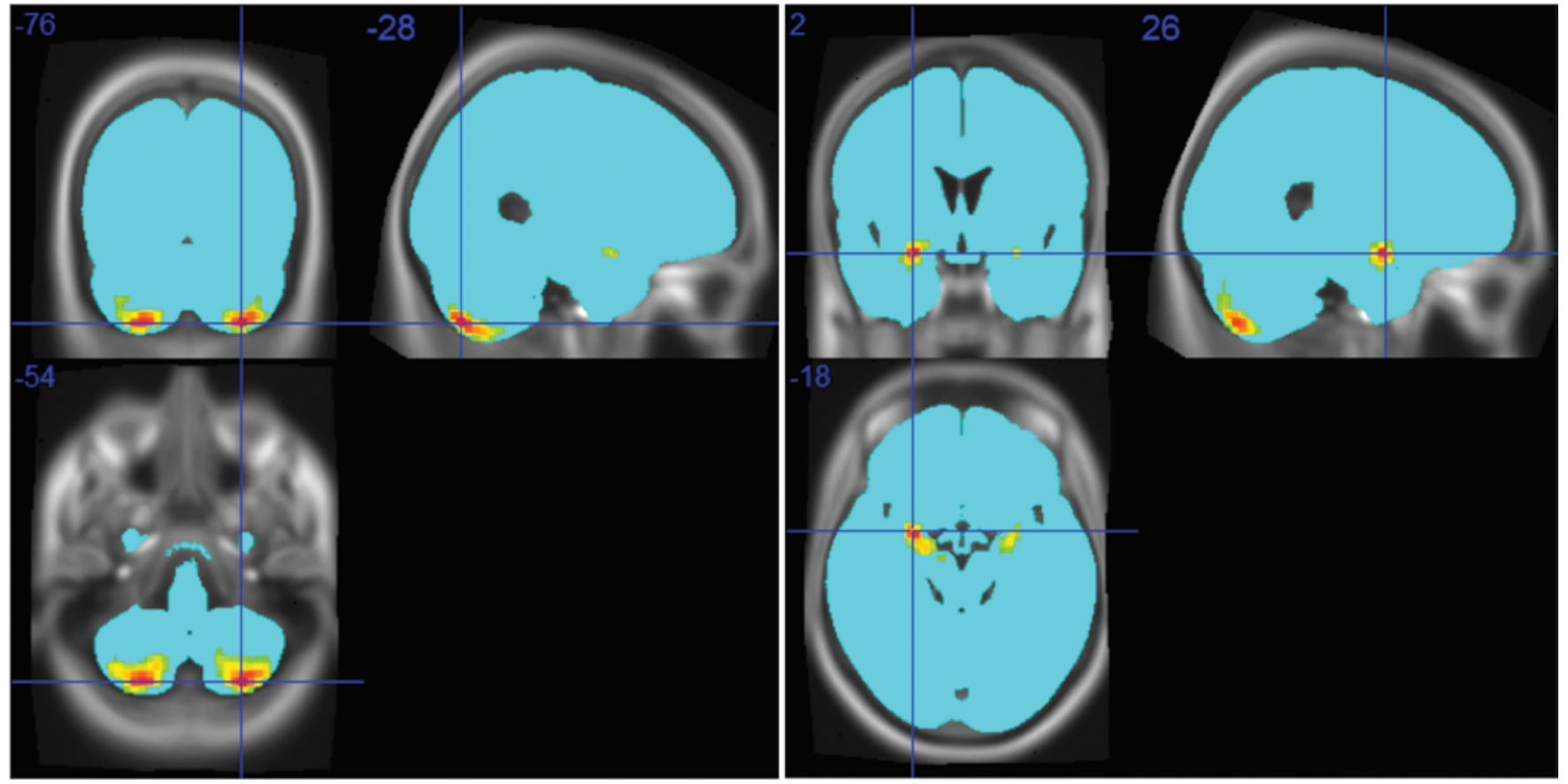

FIG. 1. Cluster topography parametric map (color map) for $p<5 E-07$ superimposed on a template in MNI space indicating areas of reduced GM. The VBM was performed for all voxels belonging to the parenchymal mask (blue). Left: Cerebellar clusters. The cross-hair center points to the location in the left cerebellum of the hottest voxel of the parametric map, which has a t score of 8.14 . The MNI coordinates are $-28,-76$, and $-54 \mathrm{~mm}$. Right: Hippocampal clusters. The cross-hair center points to the location in the right limbic system (MNI coordinates: 26, 2, -18) of the second-hottest voxel, with a t score of 8.12 .

(326 voxels; $\mathrm{t}$ score of peak $=8.12$; peak MNI 26, 2, -18 ) and $1.13 \mathrm{ml}(141$ voxels; $\mathrm{t}$ score of peak $=7.35$; peak MNI $-24,-2$, and -16$)$, respectively.

\section{Atlas-Based Volumetry}

There was a significant reduction of lateral cerebral and hippocampal volumes (adjusted to the mean age and mean
TIV of the control group) in patients with CD compared with healthy controls $(\mathrm{p}<0.0001)$ (Table 2$)$.

\section{Cerebral Volume and Tumor Markers}

Decreased bilateral hippocampal and cerebellar GM volume displayed no significant correlation to preoperative levels of cortisol (hippocampus right, $\mathrm{p}=0.869$; hip-

TABLE 2. Cluster volumes in patients with $C D$ and in healthy controls*

\begin{tabular}{lccc}
\hline Parameter & Controls & CD & p Value $\dagger$ \\
\hline Group size & 40 & 19 & \\
\hline Sex (M/F) & $(26 / 14)$ & $(3 / 16)$ & $<0.0001$ (2-tailed) \\
\hline Age in yrs & $63 \pm 12$ & $45 \pm 13$ & 0.03 (2-tailed) \\
\hline TIV in ml & $1424 \pm 113$ & $1352 \pm 124$ & 0.08 (1-tailed) \\
\hline HVR in $\mathrm{ml}$ & $3.22 \pm 0.42$ & $3.06 \pm 0.37$ & $<0.0001$ (1-tailed) \\
\hline Adj HVR in $\mathrm{ml}$ & $3.22 \pm 0.25$ & $2.90 \pm 0.26$ & 0.12 (1-tailed) \\
\hline HVL in $\mathrm{ml}$ & $3.23 \pm 0.43$ & $3.12 \pm 0.31$ & $<0.0001$ (1-tailed) \\
\hline Adj HVL in $\mathrm{ml}$ & $3.23 \pm 0.25$ & $2.89 \pm 0.28$ & 0.0005 (1-tailed) \\
\hline CVR in $\mathrm{ml}$ & $50.87 \pm 6.24$ & $44.98 \pm 5.93$ & $<0.0001$ (1-tailed) \\
\hline Adj CVR in $\mathrm{ml}$ & $50.87 \pm 4.23$ & $41.95 \pm 4.67$ & 0.0009 (1-tailed) \\
\hline CVL in $\mathrm{ml}$ & $50.42 \pm 5.87$ & $45.00 \pm 6.06$ & $<0.0001$ (1-tailed) \\
\hline Adj CVL in $\mathrm{ml}$ & $50.42 \pm 3.97$ & $42.11 \pm 4.59$ & \\
\hline
\end{tabular}

Adj = adjusted; $C V L$ = cerebellar volume left; $C V R=$ cerebellar volume right; $H V L=$ hippocampal volume left; $H V R=$ hippocampal volume right. * All volumes were adjusted to the mean TIV (1424 ml) and mean age (63 years) of the control group by using bilinear regression. Unless otherwise specified, values are expressed as the mean \pm SD .

$\dagger$ Two-sample t-test. 
pocampus left, $\mathrm{p}=0.825$; cerebellum right, $\mathrm{p}=0.796$; cerebellum left, $\mathrm{p}=0.981$ ). The duration of illness did also not affect the GM volumes or the endocrinological tumor markers.

Figures 2 and 3 demonstrate MRI findings in an illustrative case of $\mathrm{CD}$ and a healthy control.

\section{Discussion}

Our study shows that standard 3-T MRI can detect atrophic degeneration of the brain in biologically active, untreated CD. We detected 2 different regions that are subject to significant reduction of GM compared with age-adjusted healthy controls. The most significant areas of reduction of GM were the hippocampal regions and the cerebellum.

This effect of CD and CS has been described in previous studies,$^{10}$ and was discussed in relation to glucocorticoids and their neurotoxic effects. ${ }^{19}$ It has been argued that the high prevalence of mineralocorticoid receptors and glucocorticoid receptors is a possible reason for volume reduction in the hippocampus.

The hippocampus, the amygdala, and the anterior cingulate gyrus form a neural circuit, which is mainly responsible for stress reactivity. Therefore, dysfunction in this area is hypothesized to be related to mood and anxiety disorders, ${ }^{7}$ which are common symptoms in patients with CD. . $^{1,27,35,36}$

Major depressive disorder is the most common and severe psychiatric disorder associated with chronic endogenous hypercortisolism. A recent review by Pivonello and colleagues shows a prevalence of major depressive disorder in $50 \%-81 \%$ of patients with CS. Although chronic glucocorticoid overproduction is associated with atrophy of the hippocampus in patients with depression, the mechanism remains largely unknown. Decreasing glucose uptake and the toxic effect of excitatory amino acids on nervous cells are discussed, along with the theory of declining synthesis of neurotrophic factors and the hypothesis that excess glucocorticoids could suppress neurogenesis in the dentate gyrus, leading to hippocampal volume loss. ${ }^{30}$

To date only 1 study can be identified that used a similar technique in patients in long-term remission of $\mathrm{CD},{ }^{3}$ but not in those with untreated disease. In their study, Andela et al. found a significant reduction of volume of the gyrus cinguli in patients after long-term remission of CD, and they hypothesized that these changes play a role in the long-term psychological dysfunction found in patients in whom $\mathrm{CD}$ has been cured.

Changes in cerebellar volume are also known to be caused by elevated cortisol levels and stress, ${ }^{3,28}$ which may also facilitate changes in cognitive function and emotional control. ${ }^{5}$ Whereas Andela et al. found an increase in cerebellar volume in their patients 6 months after cure, our data show a lower cerebellar volume, supporting the results published by Santos et al. in 2014, ${ }^{31}$ who also found a significant reduction of cerebellar volume in patients with active CS. These findings correspond to the presence of glucocorticoid receptors in the cerebellum, ${ }^{16}$ and could explain our results of lower cerebellar volume, which are confirmed by the results of Santos et al. and Momose et al. ${ }^{28}$

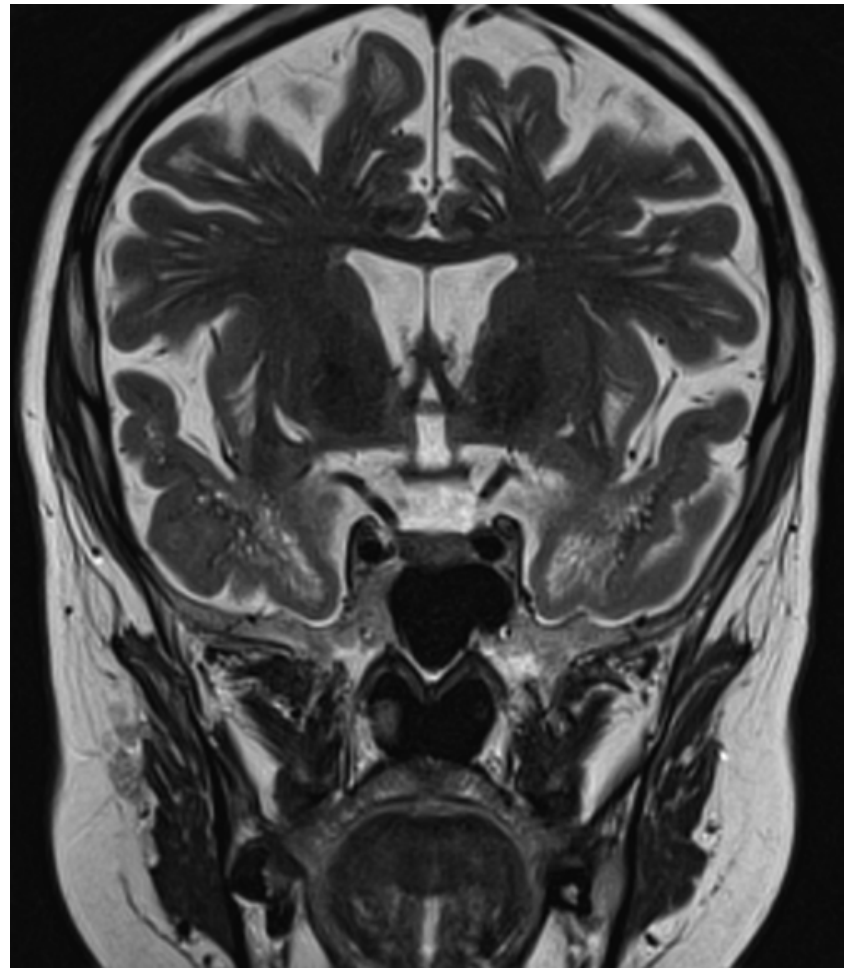

FIG. 2. Coronal T2-weighted 3-T MRI study obtained in a 20 -year-old woman with $C D$. We opted to present a T2-weighted image for better illustration of cerebral atrophy in this case.

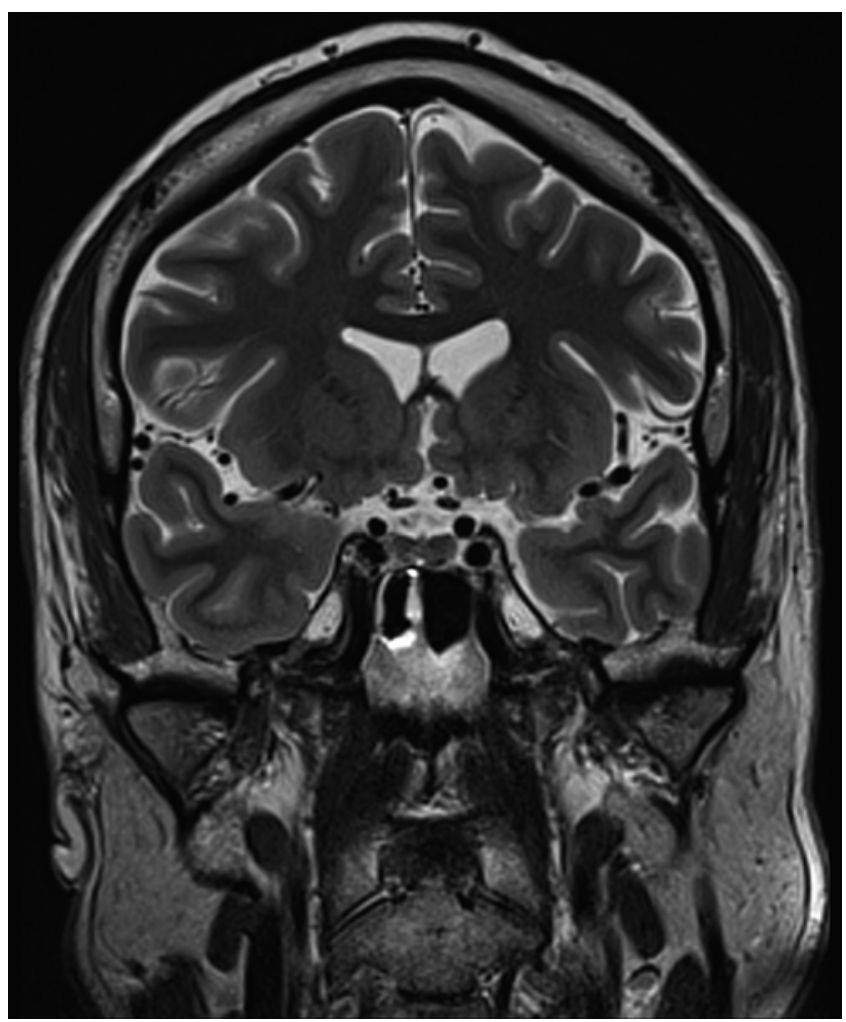

FIG. 3. Coronal T2-weighted 3-T MRI study obtained in a healthy 42-year-old man. We opted to present a T2-weighted image for better illustration of cerebral atrophy in this case. 
Interestingly, we did not find a significant correlation between the duration of illness and reduction of GM, or between the elevation of cortisol, ACTH, and DHEA-S and reduction of GM, which is most likely to be due to the relatively small sample size of only 19 patients.

\section{Conclusions}

Patients with active, untreated CD show a significant reduction of GM in both hippocampi and cerebellar hemispheres. These volume reductions are detectable on standard 3-T MRI and can be objectified by the quantitative voxel-based volumetric method described in this study. Further studies are needed to evaluate the long-term effects of GM reduction in patients with CD regarding neuroendocrinological biomarkers, duration of illness, and depressive symptoms.

\section{References}

1. Alcalar N, Ozkan S, Kadioglu P, Celik O, Cagatay P, Kucukyuruk B, et al: Evaluation of depression, quality of life and body image in patients with Cushing's disease. Pituitary 16:333-340, 2013

2. Amunts K, Kedo O, Kindler M, Pieperhoff P, Mohlberg H, Shah NJ, et al: Cytoarchitectonic mapping of the human amygdala, hippocampal region and entorhinal cortex: intersubject variability and probability maps. Anat Embryol (Berl) 210:343-352, 2005

3. Andela CD, van der Werff SJ, Pannekoek JN, van den Berg SM, Meijer OC, van Buchem MA, et al: Smaller grey matter volumes in the anterior cingulate cortex and greater cerebellar volumes in patients with long-term remission of Cushing's disease: a case-control study. Eur J Endocrinol 169:811819, 2013

4. Ashburner J: A fast diffeomorphic image registration algorithm. Neuroimage 38:95-113, 2007

5. Baumann O, Mattingley JB: Functional topography of primary emotion processing in the human cerebellum. Neuroimage 61:805-811, 2012

6. Bourdeau I, Bard C, Noël B, Leclerc I, Cordeau MP, Bélair $\mathrm{M}$, et al: Loss of brain volume in endogenous Cushing's syndrome and its reversibility after correction of hypercortisolism. J Clin Endocrinol Metab 87:1949-1954, 2002

7. Bremner JD: Functional neuroimaging in post-traumatic stress disorder. Expert Rev Neurother 7:393-405, 2007

8. Burkhardt T, Flitsch J, van Leyen P, Sauer N, Aberle J, Grzyska U, et al: Cavernous sinus sampling in patients with Cushing's disease. Neurosurg Focus 38(2):E6, 2015

9. Burkhardt T, Schmidt NO, Vettorazzi E, Aberle J, Mengel M, Flitsch J: DHEA(S) - a novel marker in Cushing's disease. Acta Neurochir (Wien) 155:479-484, 2013

10. Cerqueira JJ, Catania C, Sotiropoulos I, Schubert M, Kalisch $\mathrm{R}$, Almeida OF, et al: Corticosteroid status influences the volume of the rat cingulate cortex - a magnetic resonance imaging study. J Psychiatr Res 39:451-460, 2005

11. Chumbley JR, Friston KJ: False discovery rate revisited: FDR and topological inference using Gaussian random fields. Neuroimage 44:62-70, 2009

12. Colao A, Pivonello R, Spiezia S, Faggiano A, Ferone D, Filippella M, et al: Persistence of increased cardiovascular risk in patients with Cushing's disease after five years of successful cure. J Clin Endocrinol Metab 84:2664-2672, 1999

13. de Kloet ER, Joëls M, Holsboer F: Stress and the brain: from adaptation to disease. Nat Rev Neurosci 6:463-475, 2005

14. Eickhoff SB, Stephan KE, Mohlberg H, Grefkes C, Fink GR, Amunts K, et al: A new SPM toolbox for combining proba- bilistic cytoarchitectonic maps and functional imaging data. Neuroimage 25:1325-1335, 2005

15. Fonov V, Evans AC, Botteron K, Almli CR, McKinstry RC, Collins DL: Unbiased average age-appropriate atlases for pediatric studies. Neuroimage 54:313-327, 2011

16. Hawrylycz MJ, Lein ES, Guillozet-Bongaarts AL, Shen EH, $\mathrm{Ng}$ L, Miller JA, et al: An anatomically comprehensive atlas of the adult human brain transcriptome. Nature 489:391399,2012

17. Henley SM, Ridgway GR, Scahill RI, Klöppel S, Tabrizi SJ, Fox NC, et al: Pitfalls in the use of voxel-based morphometry as a biomarker: examples from Huntington disease. AJNR Am J Neuroradiol 31:711-719, 2010

18. Huppertz HJ, Kröll-Seger J, Klöppel S, Ganz RE, Kassubek J: Intra- and interscanner variability of automated voxelbased volumetry based on a 3D probabilistic atlas of human cerebral structures. Neuroimage 49:2216-2224, 2010

19. Joëls M, Karst H, Krugers HJ, Lucassen PJ: Chronic stress: implications for neuronal morphology, function and neurogenesis. Front Neuroendocrinol 28:72-96, 2007

20. Kelly WF, Kelly MJ, Faragher B: A prospective study of psychiatric and psychological aspects of Cushing's syndrome. Clin Endocrinol (Oxf) 45:715-720, 1996

21. Lemaître H, Crivello F, Grassiot B, Alpérovitch A, Tzourio C, Mazoyer B: Age- and sex-related effects on the neuroanatomy of healthy elderly. Neuroimage 26:900-911, 2005

22. Loosen PT, Chambliss B, DeBold CR, Shelton R, Orth DN: Psychiatric phenomenology in Cushing's disease. Pharmacopsychiatry 25:192-198, 1992

23. Lüdecke DK, Flitsch J, Knappe UJ, Saeger W: Cushing's disease: a surgical view. J Neurooncol 54:151-166, 2001

24. McEwen BS: Physiology and neurobiology of stress and adaptation: central role of the brain. Physiol Rev 87:873-904, 2007

25. McEwen BS, Eiland L, Hunter RG, Miller MM: Stress and anxiety: structural plasticity and epigenetic regulation as a consequence of stress. Neuropharmacology 62:3-12, 2012

26. Merke DP, Giedd JN, Keil MF, Mehlinger SL, Wiggs EA, Holzer S, et al: Children experience cognitive decline despite reversal of brain atrophy one year after resolution of Cushing syndrome. J Clin Endocrinol Metab 90:2531-2536, 2005

27. Milian M, Honegger J, Gerlach C, Psaras T: Health-related quality of life and psychiatric symptoms improve effectively within a short time in patients surgically treated for pituitary tumors - a longitudinal study of 106 patients. Acta Neurochir (Wien) 155:1637-1645, 2013

28. Momose KJ, Kjellberg RN, Kliman B: High incidence of cortical atrophy of the cerebral and cerebellar hemispheres in Cushing's disease. Radiology 99:341-348, 1971

29. Pivonello R, De Martino MC, De Leo M, Tauchmanovà L, Faggiano A, Lombardi G, et al: Cushing's syndrome: aftermath of the cure. Arq Bras Endocrinol Metabol 51:13811391, 2007

30. Pivonello R, Simeoli C, De Martino MC, Cozzolino A, De Leo M, Iacuaniello D, et al: Neuropsychiatric disorders in Cushing's syndrome. Front Neurosci 9:129, 2015

31. Santos A, Resmini E, Crespo I, Pires P, Vives-Gilabert Y, Granell E, et al: Small cerebellar cortex volume in patients with active Cushing's syndrome. Eur J Endocrinol 171:461469, 2014

32. Simmons NE, Do HM, Lipper MH, Laws ER Jr: Cerebral atrophy in Cushing's disease. Surg Neurol 53:72-76, 2000

33. Sonino N, Fava GA, Raffi AR, Boscaro M, Fallo F: Clinical correlates of major depression in Cushing's disease. Psychopathology 31:302-306, 1998

34. Starkman MN, Giordani B, Berent S, Schork MA, Schteingart DE: Elevated cortisol levels in Cushing's disease are associated with cognitive decrements. Psychosom Med 63:985-993, 2001

35. Tiemensma J, Biermasz NR, Middelkoop HA, van der Mast 
RC, Romijn JA, Pereira AM: Increased prevalence of psychopathology and maladaptive personality traits after longterm cure of Cushing's disease. J Clin Endocrinol Metab 95:E129-E141, 2010

36. van Aken MO, Pereira AM, Biermasz NR, van Thiel SW, Hoftijzer HC, Smit JW, et al: Quality of life in patients after long-term biochemical cure of Cushing's disease. J Clin Endocrinol Metab 90:3279-3286, 2005

37. van der Werff SJ, Andela CD, Nienke Pannekoek J, Meijer OC, van Buchem MA, Rombouts SA, et al: Widespread reductions of white matter integrity in patients with long-term remission of Cushing's disease. Neuroimage Clin 4:659 667, 2014

38. Webb SM, Badia X, Barahona MJ, Colao A, Strasburger CJ, Tabarin A, et al: Evaluation of health-related quality of life in patients with Cushing's syndrome with a new questionnaire. Eur J Endocrinol 158:623-630, 2008

\section{Disclosure}

The authors report no conflict of interest concerning the materi- als or methods used in this study or the findings specified in this paper.

\section{Author Contributions}

Conception and design: Burkhardt, Flitsch. Acquisition of data: Burkhardt, Spies, Flitsch. Analysis and interpretation of data: Burkhardt, Lüdecke, Spies. Drafting the article: Burkhardt, Lüdecke. Critically revising the article: Burkhardt, Lüdecke, Westphal, Flitsch. Reviewed submitted version of manuscript: Burkhardt, Lüdecke, Spies. Approved the final version of the manuscript on behalf of all authors: Burkhardt. Statistical analysis: Lüdecke, Spies, Wittmann. Administrative/technical/material support: Westphal. Study supervision: Burkhardt, Flitsch.

\section{Correspondence}

Till Burkhardt, Abteilung für Neurochirurgie, Universitätsklinikum Hamburg-Eppendorf, Martinistrasse 52, 20251 Hamburg, Germany. email: tburkhar@uke.de. 